\title{
Non-destructive Sampling Method for Environmental and Geochemical Exploration Studies and XRF Determination of $\mathrm{Cl}, \mathrm{F}$, and $\mathrm{Br}$
}

\author{
A. Keshav Krishna*, K. Rama Mohan, and M. Satyanarayanan \\ National Geophysical Research Institute \\ (Council of Scientific \& Industrial Research) \\ Hyderabad-500007, India
}

\begin{abstract}
In this study, halogens are determined in rocks, soils, and sediments using sequential wavelength dispersive X-ray fluorescence spectrometry (WDXRF) by means of a non-destructive sampling method from powder to pellet form. A calibration procedure is introduced which provides accurate data, and the detection limits of halogens which were verified with different geological reference materials. The sample powders with a $74 \mu \mathrm{m}$ particle size were used to prepare pressed pellets. A set of 25 reference materials was scanned for calibration of the spectrometer, and another set of 11 reference materials was analyzed for evaluation of the accuracy. The analytical data obtained for the standard samples ranged from $26 \mathrm{mg} / \mathrm{kg}-1200 \mathrm{mg} / \mathrm{kg}$ for $\mathrm{Cl}, 44 \mathrm{mg} / \mathrm{kg}-6960 \mathrm{mg} / \mathrm{kg}$ for $\mathrm{F}$, and $0.71 \mathrm{mg} / \mathrm{kg}-252 \mathrm{mg} / \mathrm{kg}$ for $\mathrm{Br}$.
\end{abstract}

These studies have also shown that standard pellets made from $2 \mathrm{~g}$ of powder are critically thick enough in measuring the final detection limits for $\mathrm{Cl}, \mathrm{F}$, and Br. Further, the analytical results obtained for halogens show mean RSD values ranging from $0.78 \%$ to $6.7 \%$ for $\mathrm{Cl}, 0.86 \%$ to $5.23 \%$ for $\mathrm{F}$, and $0.01 \%$ to $0.59 \%$ for Br. The order of suitability of reference materials for halogen determination in this study is Basaltic rocks (BEN, BHVO-1, BIR-1) > Syenites (STM1, SY-2) > Rhyolites (JR-1, JR-2, RGM-1). The fitness for purpose of the results was also evaluated using the quality test proposed by the International Global Geochemical Mapping Program (IGCP), from which it can be deduced that the method is adequate for geochemical mapping applications.

\section{INTRODUCTION}

Halogens are of major interest in geochemical research and for environmental studies. Despite their naturally low concentrations, halogens are thought to play an important role in the evolution of magmatic systems and associated ore deposits, and can have a negative environmental impact. In this study, the determination of halo-

\footnotetext{
*Corresponding autbor.

E-mail: keshav_krishna@ngri.res.in E-mail: Keshav_aradbi@yaboo.com Tel. : +91040-23434671

Fax: +91-040-23434651
}

gens in powdered rocks, soils, and sediments was performed using $\mathrm{X}$-ray fluorescence (XRF). This is a non-destructive method with the advantage that the total element content of the sample can be measured using the non-destructive sampling method from powder to pellet form.

Halogens (chlorine, fluorine, and bromine) are one of the most important groups of elements in the study of geochemical science. They have long been recognized as valuable indicators for petrogenesis and used for environmental science studies due to their high volatilities and their geochemical behavior which provides information on their significant role in exploration geochemistry.

The geochemistry of the naturally occurring halogens has some similarities with chlorine $(\mathrm{Cl})$, fluorine $(\mathrm{F})$, and bromine $(\mathrm{Br})$. They are classified as lithophile elements due to their concentration in silicate minerals. Indeed, $\mathrm{F}$ and $\mathrm{Cl}$ concentrations in the majority of silicate metals rarely exceed $5000 \mathrm{ppm}$, and bromine rarely exceeds 250 ppm $(1,2,3)$. Although much work has been carried out on the geochemistry of halogens and their influence on human health, there is a paucity of available data. Since halogen concentrations in geological rock samples are generally low, ranging from $\mu \mathrm{g} / \mathrm{g}$ (for fluorine and chlorine) to $\mathrm{ng} / \mathrm{g}$ (for bromine and iodine), non-destructive sampling methods with X-ray fluorescence (XRF) and electron-probe X-ray analysis are difficult to apply.

Several reasons explain the wide acceptance of XRF for the determination of $\mathrm{Cl}, \mathrm{F}$, and $\mathrm{Br}$ since sample preparation is simple and offers instrumental precision and longevity of the calibrations. Ion chromatography (IC) has become a traditional technique for $\mathrm{F}$ and $\mathrm{Cl}$ measurements in solutions, and depending on the Br content, it may also be determined by IC with good accuracy (4). However, limited literature is available with regard to the measurement of halogens (especially $\mathrm{Br}$ ) in geological reference materials, and large variations exist between reported values in igneous rocks vs. sedimentary rocks or soils. Studies on the determination of halogens $(\mathrm{F}, \mathrm{Cl}, \mathrm{Br}, \mathrm{I})$ 
in different geochemical reference materials $(5,4)$ have been carried out by using powdered samples and the pyrohydrolysis technique where the whole sample is melted by heating.

In the present study, the halogens were determined using pressed powder pellets. The spectral lines used in most natural samples lie at a shorter (higher energy) wavelength than those of the associated major and trace elements, and the major problem to overcome is that of absorption. The simplest, and probably the most effective, approach to correct for absorption makes use of the fact that the intensity of the background, and of the coherent and incoherent scattered lines of the anode elements, vary systematically with the mass absorption of the sample matrix. Measurement of this scattered radiation (usually that of the Compton $\mathrm{K} \alpha$ for most anodes) provides an absorption correction factor $(6,7)$.

The purpose of the present study was to develop a quantitative analytical XRF method for the routine analysis of geological rock materials, as well as soils and sediments. For this type of application, the homogeneity and particle size of the sample powders can significantly influence the quality of the final results. Besides sample preparation, the final accuracy depends strongly on the calibration strategy, which was evaluated as thoroughly as possible by the analysis of reference materials. The results were judged by fitness of accuracy as well as the detection limits. For complex samples, a frequent calibration strategy is to use matrixmatched reference materials, ideally certified for the constituents of interest. In this work, 25 international rock, soil, and sediment reference materials were scanned and 11 reference materials were selected to calibrate the instrument for halogen determination.

Keeping in view the negative contribution of $\mathrm{Cl}, \mathrm{F}$, and $\mathrm{Br}$ to the environment, an attempt has been made to investigate and evaluate the ability of the XRF instrument for the in situ and rapid determination of halogens $(\mathrm{Cl}, \mathrm{F}$, and $\mathrm{Br})$ in rock, soil, and sediment samples for environmental and geochemical exploration studies.

\section{EXPERIMENTAL}

\section{Instrumentation}

A Philips MagiX PRO Model PW 2440 wavelength dispersive X-ray fluorescence spectrometer, coupled with an automatic sample changer Model PW 2540 (Philips, Eindhoven, The Netherlands), was used for this study. The MagiX PRO is a sequential instrument with a single goniometer-based measuring channel, covering the complete elemental measurement range from $\mathrm{F}$ to $\mathrm{U}$ in the concentration range of $1.0 \mathrm{ppm}$ to \% levels. The instrument

TABLE I

Instrumental Conditions Used for $\mathrm{X}$-ray Fluorescence Spectrometer

\begin{tabular}{|c|c|c|c|c|c|c|c|c|c|}
\hline $\begin{array}{c}\text { Ele- } \\
\text { ment } \\
\text { Traces }\end{array}$ & Line & $\mathrm{Cr}$ & De & $\mathrm{kV}$ & $\mathrm{mA}$ & $\begin{array}{l}\text { Peak } \\
(2 \theta)\end{array}$ & $\begin{array}{c}\text { Bkg } \\
( \pm 2 \theta)\end{array}$ & $\begin{array}{l}\text { Counting } \\
\text { Time(s) }\end{array}$ & $\begin{array}{c}\text { Line/ } \\
\text { Overlap } \\
\text { Correction }\end{array}$ \\
\hline $\mathrm{Cl}$ & $\mathrm{K} \alpha$ & $1-\mathrm{C}$ & & 50 & 40 & 8 & 1.8806 & & $\mathrm{~F}, \mathrm{Br} / \mathrm{a}$ \\
\hline $\mathrm{F}$ & $\mathrm{K} \alpha$ & PX 1 & Flow $^{\mathrm{a}}$ & 30 & 70 & 43.5998 & 2.1330 & $60+40$ & Cl,Br/alpha \\
\hline $\mathrm{Br}$ & $\mathrm{K} \alpha$ & PX 9 & Scint. ${ }^{b}$ & 60 & 66 & 29.9242 & 0.9472 & $60+40$ & $\mathrm{Cl} /$ alpha \\
\hline
\end{tabular}

\footnotetext{
${ }^{a}$ Flow proportional and sealed xenon counter.
}

${ }^{\mathrm{b}}$ Scint. $=$ Scintillation counter .

\section{Atomic Apectroscopy 1 Vol. 33(3), May/June 2012}

is microprocessor-controlled for maximum flexibility and consists of an end-window X-ray tube with an $\mathrm{Rh}$ anode and a maximum voltage/ current of $60 \mathrm{kV} / 125 \mathrm{~mA}$ at a maximum power level of $4 \mathrm{~kW}$. The analytical lines and instrumental parameters used for measurement of the halogens are listed in Table I.

For the vast amount of geochemical work, most elements are known to fall within certain ranges, which were considered when selecting the operating conditions. In general, one set of operating conditions is sufficient for each element, designed initially to avoid spectral overlaps (on peaks and backgrounds) and to optimize the count rate. Also, where the choice exists, it is preferable to count for a longer period on a well-separated peak than to introduce a correction for overlapping peaks. In quantitative analysis, the intensity of any given line is proportional to the concentration, but is modified by a combination of absorption and enhancement effects which are, in turn, a function of the composition of the sample and the primary spectrum from the X-ray tube $(6,8,9)$.

To compensate for possible instrument drift, a monitor sample was analyzed at the beginning and at the end of each day when the samples were run. The net intensities were calculated by subtracting the background from the raw peak intensity. The net intensity (or raw intensity where background levels were not measured) for a given element divided by the average of the two monitor sums for the day gives the monitor-normalized intensity. The difference in count rate of the monitor between the start and the end of the day was typically $+0.2 \%$ relative to the mean of the two runs of the day. 
Samples, Standards, and Their Preparation

The measured intensity, rather than the concentration of the elements, was used since the aim was to check the precision of the method rather than the accuracy. All the standard samples were used as received without drying because of concerns about loss of volatiles as well as losses incurred during sample pulverization. Pressed pellets (40 $\mathrm{mm}$ diameter) were prepared by using collapsible aluminum cups (6). These cups were filled with boric acid and about $2 \mathrm{~g}$ of the finely powdered sample, and mixed. This mixture was pressed into a pellet using a hydraulic press at 25-ton pressure (Hydraulic Press, Herzog, Germany). The sample was considered to be homogeneous since the variation in counts per second of the X-ray intensity was less than $1 \%$, indicating that the concern regarding loss of sample or contamination of the sample was taken into consideration.

\section{Calibration}

The spectrometer was calibrated after measuring the intensities of 25 international reference materials (RMs) (rock, soil, and sediment) which are listed in Table II and obtained from the literature of Govindaraju et al. (10). The criteria for selecting these samples were the required interval of concentration, the quality of the known data, and previous calibration tests. Table III provides the reference values for these 11 reference materials. Table IV lists the range of concentrations for $\mathrm{Cl}, \mathrm{F}$, and $\mathrm{Br}$ found during instrument calibration. Figure 1 shows the range of concentrations for $\mathrm{Cl}, \mathrm{F}$, and $\mathrm{Br}$ that fitted into the calibration curve to obtain a straight line. The correlation coefficient was 0.9994 for $\mathrm{Cl}$, 0.9997 for $\mathrm{F}$, and 0.9997 for $\mathrm{Br}$.

Table II

Details of International Reference Materials Studied

\begin{tabular}{|c|c|c|}
\hline $\begin{array}{l}\text { Sample } \\
\text { No. }\end{array}$ & $\begin{array}{l}\text { Reference Material } \\
\text { Sample Name }\end{array}$ & Source \\
\hline 1. & AGV-1 (Andesite) & USGS, United States Geological Survey, Reston \\
\hline 2. & ANG (Anorthosite) & GIT-IWG, Groupe International de Travail-International Working Group \\
\hline 3. & ASK-3 (Sulphide ore) & Analytisk Sporelement Komite, Oslo, Norway \\
\hline 4. & BCR-1 (Basalt) & USGS, United States Geological Survey, Reston \\
\hline 5. & BEN (Basalt) & GIT-IWG, Groupe International de Travail-International Working Group \\
\hline 6. & BHVO-1 (Basalt) & USGS, United States Geological Survey, Reston \\
\hline 7. & BIR-1 (Basalt) & USGS, United States Geological Survey, Reston \\
\hline 8. & G-2 (Granite) & USGS, United States Geological Survey, Reston \\
\hline 9. & GSP-1 (Granodiorite) & USGS, United States Geological Survey, Reston \\
\hline 10. & GSR-1 (Granite) & IGGE, Institute of Geophysical and Geochemical prospecting, P.R. China \\
\hline 11. & GSR-4 (Sandstone) & IGGE, Institute of Geophysical and Geochemical prospecting, P,R. China \\
\hline 12. & GSR-6 (Limestone) & IGGE, Institute of Geophysical and Geochemical prospecting, P.R. China \\
\hline 13. & GXR-2 (Soil) & USGS, United States Geological Survey, Reston \\
\hline 14. & GXR-3 (Soil) & USGS, United States Geological Survey, Reston \\
\hline 15. & GXR-4 (Coppermill-Head) & USGS, United States Geological Survey, Reston \\
\hline 16. & JA-1 (Andesite) & GSJ, Geological Survey of Japan \\
\hline 17. & JB-3 (Basalt) & GSJ, Geological Survey of Japan \\
\hline 18. & JR-1 (Rhyolite) & GSJ, Geological Survey of Japan \\
\hline 19. & JR-2 (Rhyolite) & GSJ, Geological Survey of Japan \\
\hline 20. & MAG-1 (Marine Mud) & USGS, United States Geological Survey, Reston \\
\hline 21. & NIM-L (Lujavrite) & MINTEK, Council for Mineral Technology, South Africa \\
\hline 22. & RGM-1 (Rhyolite) & USGS, United States Geological Survey, Reston \\
\hline 23. & SO-1 (Soil) & CCRMP, Canadian Certified Reference Materials Project, Canada \\
\hline 24. & STM-1 (Syenite) & USGS, United States Geological Survey, Reston \\
\hline 25. & SY-2 (Syenite) & CCRMP, Canadian Certified Reference Materials Project, Canada \\
\hline
\end{tabular}




\section{Atomic Spectroscopy \\ $\bigcup$ Vol. 33(3), May/June 2012}

Table III

Reference Values for the Reference Materials (values in $\mathbf{m g} / \mathbf{k g}$ )

\begin{tabular}{lrrr}
\hline S.No/Sample & \multicolumn{1}{c}{ Cl } & \multicolumn{1}{c}{$\mathrm{F}$} & \multicolumn{1}{c}{$\mathrm{Br}$} \\
\hline 1. AGV-1 & 119 & 425 & 0.32 \\
2. ANG & 300 & 120 & $\mathrm{a}$ \\
3. ASK-3 & 9.0 & 800 & $\mathrm{a}$ \\
4. BCR-1 & 59 & 490 & 0.07 \\
5. BEN & 200 & 1000 & $\mathrm{a}$ \\
6. BHVO-1 & 92.0 & 385 & 0.71 \\
7. BIR-1 & 26.0 & 44.0 & 2.3 \\
8. G-2 & 70 & 1280 & 0.2 \\
9. GSP-1 & 330 & 3630 & 0.52 \\
10. GSR-1 & 127 & 2350 & $\mathrm{a}$ \\
11. GSR-4 & 42 & 183 & $\mathrm{a}$ \\
12. GSR-6 & 80 & 406 & $\mathrm{a}$ \\
13. GXR-2 & $\mathrm{a}$ & 450 & 3.2 \\
14. GXR-3 & $\mathrm{a}$ & 86200 & $\mathrm{a}$ \\
15. GXR-4 & 78 & 2840 & 0.5 \\
16. JA-1 & 35 & 180 & 7.0 \\
17. JB-3 & 260 & 295 & $\mathrm{a}$ \\
18. JR-1 & 920.0 & 942.0 & 10.0 \\
19. JR-2 & 730 & 1087 & $\mathrm{a}$ \\
20. MAG-1 & 310,000 & 770 & 252 \\
21. NIM-L & 1200 & 4400 & $\mathrm{a}$ \\
22. RGM-1 & 510 & 342 & 1.34 \\
23. SO-1 & 150 & 850 & 2.0 \\
24. STM-1 & 460 & 910 & 2.3 \\
25. SY-2 & 140 & 5030 & $\mathrm{a}$ \\
\hline Va
\end{tabular}

${ }^{a}$ Values not provided.

Table IV

Concentration Interval Covered by Reference Materials Used to Calibrate the Spectrometer

\begin{tabular}{cc}
\hline $\begin{array}{c}\text { Halogens } \\
(\mathrm{mg} / \mathrm{kg})\end{array}$ & Concentration \\
\hline $\mathrm{Cl}$ & $26-1200$ \\
$\mathrm{~F}$ & $44-6960$ \\
$\mathrm{Br}$ & $0.71-252$ \\
\hline
\end{tabular}
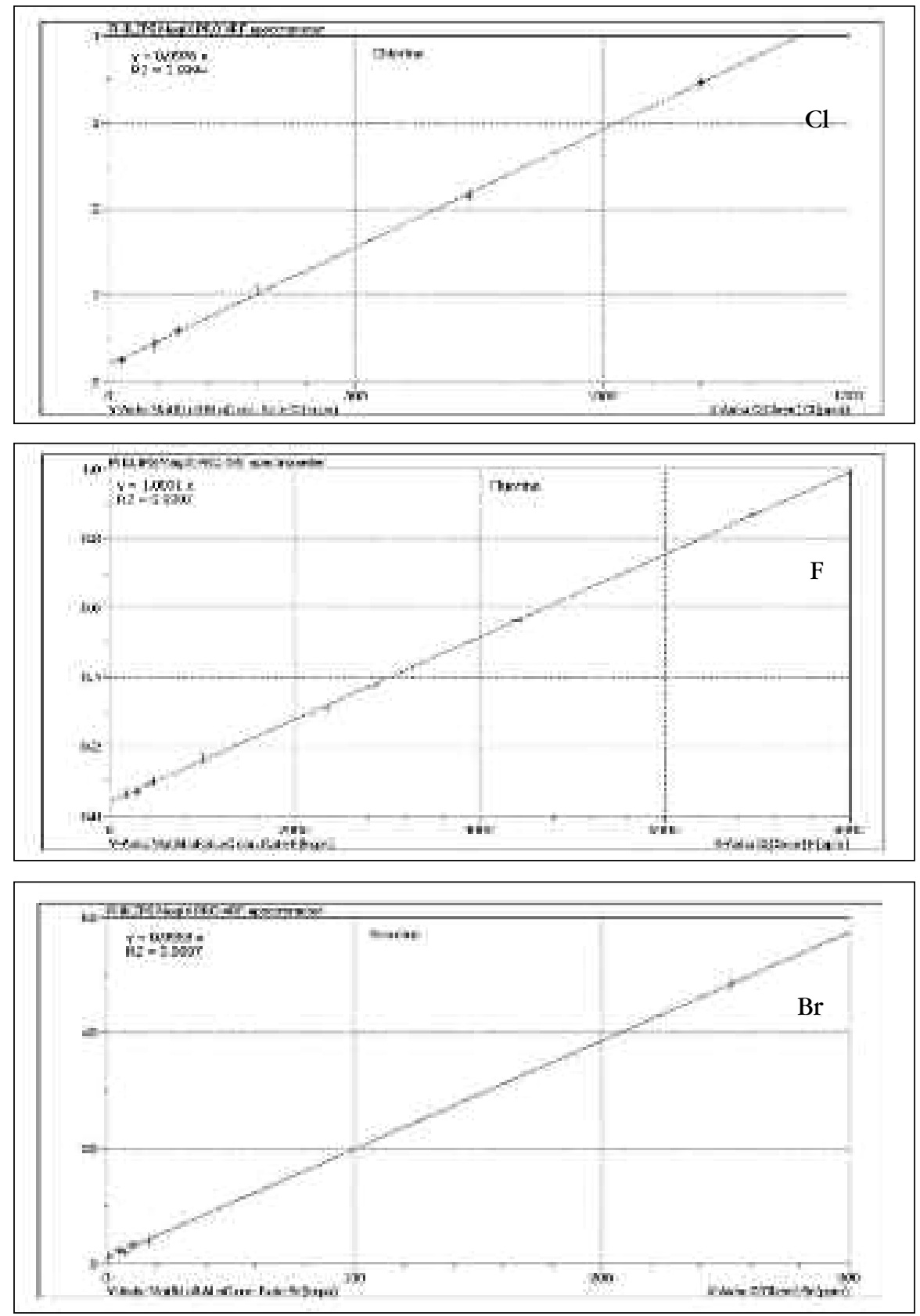

Fig. 1. Calibration curves for $\mathrm{Cl}, \mathrm{F}$, and $\mathrm{Br}$. 


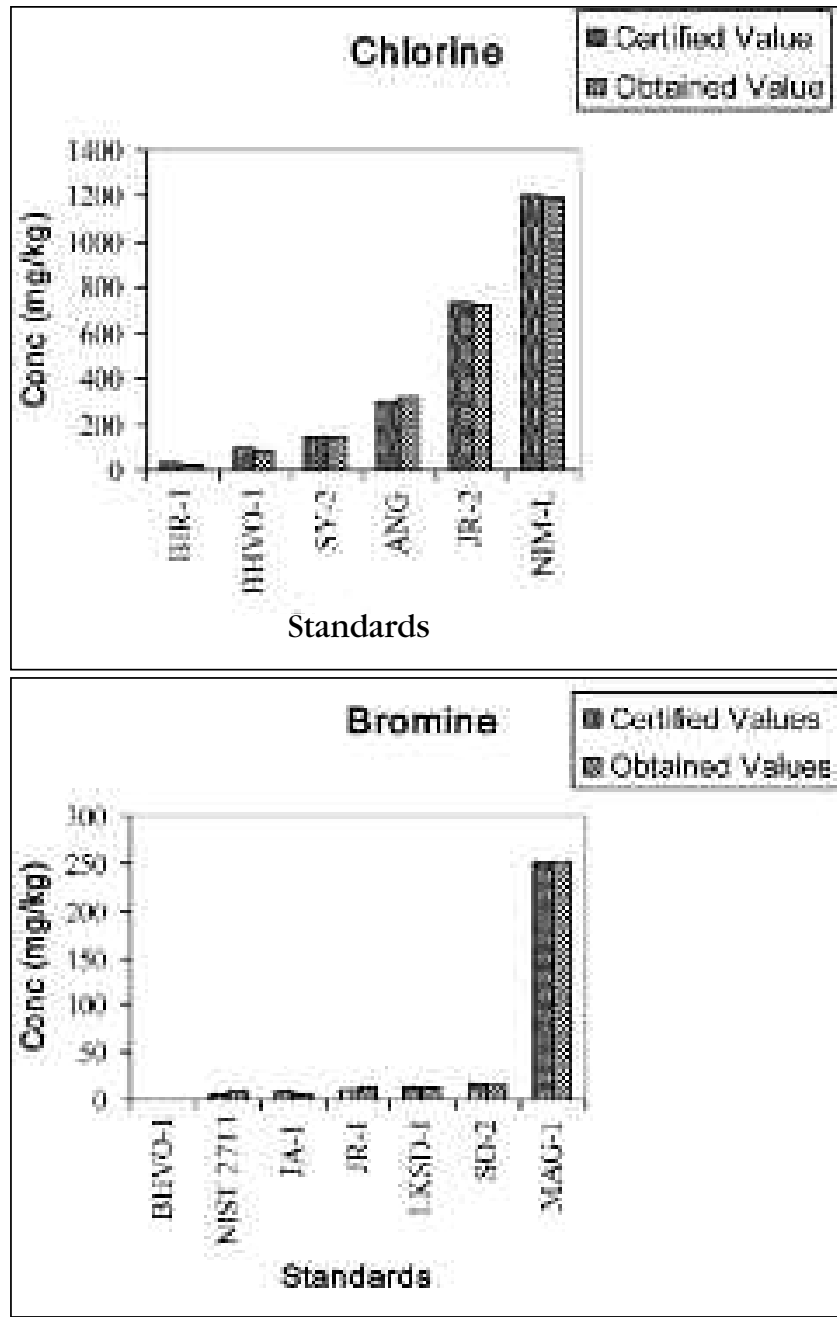

Fig. 2. Bar chart showing the reference materials used for $\mathrm{Cl}, \mathrm{F}$, and $\mathrm{Br}$, and comparison with obtained value and certified value.

Figure 2 is a comparison of certified vs. obtained concentrations for $\mathrm{Cl}$ with six $\mathrm{RMs}$, F with nine RMs, and $\mathrm{Br}$ with seven RMs. The tables and figures which are discussed in detail show the detection limits, accuracy, and precision in the determination of the halogens (Cl, F, and Br) in rock, soil, and sediment samples for environmental and geochemical exploration.

\section{RESULTS AND DISCUSSION}

Table $\mathrm{V}$ lists the concentrations of the halogens obtained in this work (presented with the associated uncertainty) and the certified values. The uncertainty includes the sum of the following components: counting statistics, systematic errors in background calculation, and spectral correction and sensitivities used to calibrate the spectrometer. All data were obtained for single pellet analysis, measuring for triplicate analysis $(n=3)$ for each reference sample.

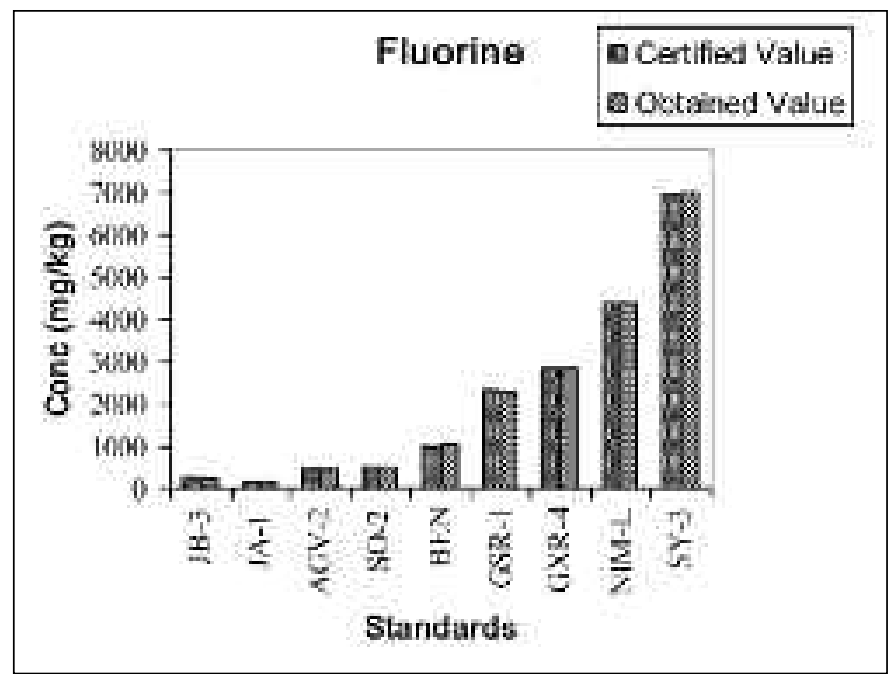

Table V

Analytical Results Obtained for Halogens (values in $\mathbf{m g} / \mathbf{k g}$ )

\begin{tabular}{|c|c|c|c|c|}
\hline S.No & Sample & $\mathrm{Cl}$ & $\mathrm{F}$ & $\mathrm{Br}$ \\
\hline \multirow[t]{2}{*}{1} & ANG & $329.7 \pm 4.9^{a}$ & $113.1 \pm 2.6$ & $10.7 \pm 0.33$ \\
\hline & & $300^{\mathrm{b}}$ & $120^{\mathrm{b}}$ & c \\
\hline \multirow[t]{2}{*}{2} & BEN & $236 \pm 2.4$ & $1024 \pm 2.3$ & $0.78 \pm 0.01$ \\
\hline & & $200^{\mathrm{b}}$ & $1000^{\mathrm{b}}$ & $\mathrm{c}$ \\
\hline \multirow[t]{2}{*}{3} & BHVO-1 & $102 \pm 4.2$ & $374.5 \pm 1.81$ & $0.95 \pm 0.01$ \\
\hline & & $92.0^{\mathrm{b}}$ & $385^{b}$ & $0.71^{\mathrm{b}}$ \\
\hline \multirow[t]{2}{*}{4} & BIR-1 & $22.4 \pm 1.21$ & $35.0 \pm 0.86$ & $2.22 \pm 0.29$ \\
\hline & & $26.0^{\mathrm{b}}$ & $44.0^{\mathrm{b}}$ & $2.3^{\mathrm{b}}$ \\
\hline \multirow[t]{2}{*}{5} & JR-1 & $883.3 \pm 3.7$ & $974.7 \pm 5.23$ & $10.7 \pm 0.59$ \\
\hline & & $920.0^{\mathrm{b}}$ & $942.0^{\mathrm{b}}$ & $10.0^{\mathrm{b}}$ \\
\hline \multirow[t]{2}{*}{6} & JR-2 & $725.9 \pm 0.78$ & $951.4 \pm 3.39$ & $11.8 \pm 0.40$ \\
\hline & & $730^{\mathrm{b}}$ & $1087^{\mathrm{b}}$ & c \\
\hline \multirow[t]{2}{*}{7} & MAG-1 & $29,9893 \pm 2.02$ & $685.9 \pm 2.55$ & $252 \pm 0.01$ \\
\hline & & $310,000^{\mathrm{b}}$ & $770^{\mathrm{b}}$ & $252^{\mathrm{b}}$ \\
\hline \multirow[t]{2}{*}{8} & NIM-L & $1186 \pm 4.18$ & $4388 \pm 4.60$ & $0.77 \pm 0.16$ \\
\hline & & $1200^{\mathrm{b}}$ & $4400^{\mathrm{b}}$ & c \\
\hline \multirow[t]{2}{*}{9} & RGM-1 & $459 \pm 5.0$ & $311 \pm 4.18$ & $3.12 \pm 0.51$ \\
\hline & & $510^{\mathrm{b}}$ & $342^{\mathrm{b}}$ & $1.34^{\mathrm{b}}$ \\
\hline \multirow[t]{2}{*}{10} & STM-1 & $508.1 \pm 6.7$ & $823.7 \pm 3.95$ & $4.68 \pm 0.33$ \\
\hline & & $460^{\mathrm{b}}$ & $910^{\mathrm{b}}$ & $2.3^{\mathrm{b}}$ \\
\hline \multirow[t]{2}{*}{11} & SY-2 & $148.3 \pm 2.54$ & $4995 \pm 3.09$ & $6.55 \pm 0.23$ \\
\hline & & $140^{\mathrm{b}}$ & $5030^{\mathrm{b}}$ & c \\
\hline
\end{tabular}

${ }^{a}$ First row values of each sample were obtained in this work $( \pm 1 S, n=3)$.

${ }^{\mathrm{b}}$ Second row values are certified values, issued by the producers of the reference materials.

${ }^{\mathrm{c}}$ Values not provided. 


\section{Atomic Apectroscopy \\ $\bigcirc$ Vol. 33(3), May/June 2012}

Most well-characterized geological reference materials, i.e., those with reference values and associated uncertainties for almost every element present at detectable concentrations, are of common silicate matrices. When reference materials with abnormally high concentrations of halogens are needed, it is difficult to find reference values and their associated uncertainties to permit calibration of the spectrometer. As a consequence, difficulties arise when samples with anomalously high concentrations of one or more produce acceptable calibration. When based on intensities, matrix correction is achieved by trial and error and is mainly based on which elements would more strongly absorb the emitted intensities of the element of interest. Matrix corrections based on empirical coefficients are only valid for the analysis of samples with a composition within the interval of the standard. For this reason, reference materials with unusually high concentrations are also included as standards. The results obtained for eleven RMs in this study are compared to reported data (Table V). Very few data have been published for $\mathrm{Br}$ in igneous rock reference materials. It can be seen that the detection limits and precisions of the XRF technique used in this study are better than indicated by repeatabilities on the reference materials.

\section{Detection Limits}

An important statistical consideration for using XRF analysis is the capability of the instrument to detect whether an element is present at a concentration greater than a certain limit. The most current detection limit used in XRF analysis is the lower limit of detection, which is assumed to be the concentration equivalent to three standard counting errors of a set of measurements of the background intensity (11). The expression "lower limit of
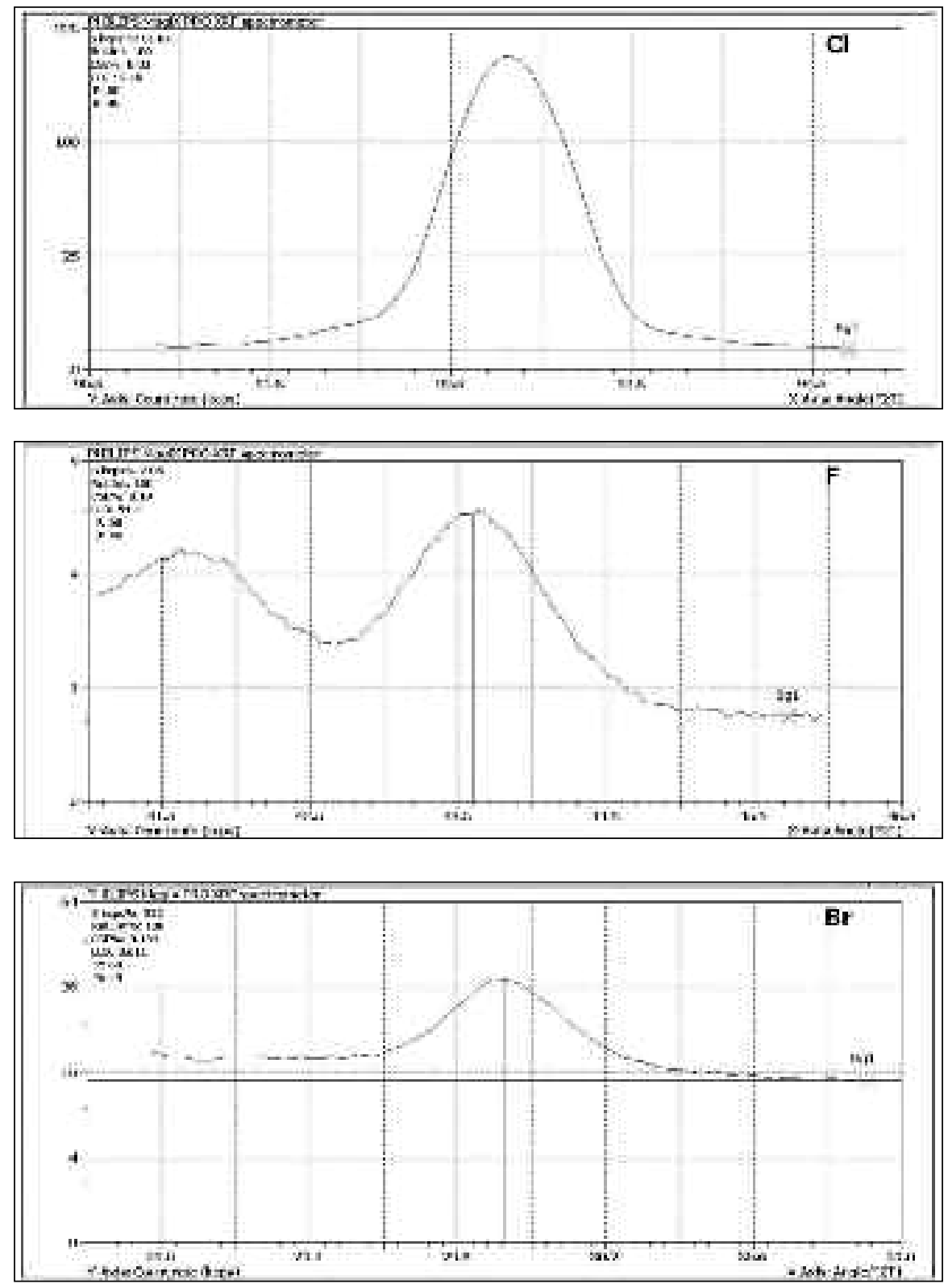

Fig. 3. Scan of halogens ( $\mathrm{Cl}, \mathrm{F}, \mathrm{Br})$ in geological reference materials with a Philips $P W 2440$ X-ray Spectrometer representing detection and counting of statistical error (CSE).

detection" (LLD) is often used in the literature for X-ray analysis and represents the smallest amount of an element that can be detected in a specific statistical context for a given matrix. In this study using the PW 2440 spectrometer, we were able to scan the halogen elements (Cl, F, Br) to calculate the counting statistical error (CSE) and the lowest limit of detection (LLD) for selected counting times on peaks and backgrounds. When reasonable times are selected (60 peak - 40 background), the LLD and CSE are good (Figure 3). These studies also show that standard pellets made from $2 \mathrm{~g}$ of powder are critically 


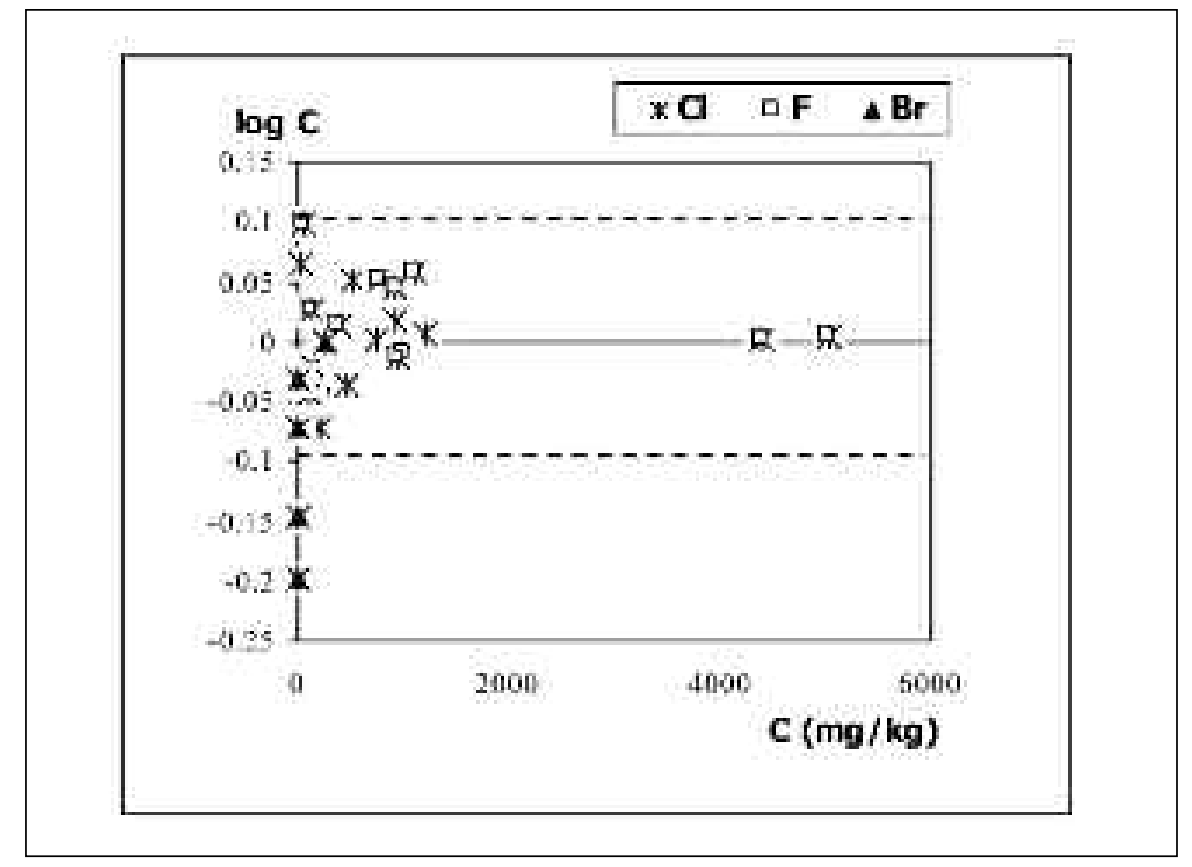

Fig. 4. Test proposed by IGCP for accuracy evaluation in geochemical mapping, Results obtained for halogens are displayed, taking $\log C c-\log C f(C c=$ certified and $C f=$ found concentration). The plot's external lines represent the expected accuracy for first-grade standards (e.g., international reference materials), while the internal interrupted lines represent the accuracy expected for second-grade standards.

thick enough for measuring $\mathrm{Cl}, \mathrm{F}$, and $\mathrm{Br}$. However, the line intensity measuring conditions are the most important factor in determining the final detection limit.

\section{Accuracy}

Table $\mathrm{V}$ lists the analytical results obtained for the halogens $\mathrm{Cl}, \mathrm{F}$, and $\mathrm{Br}$ in 11 international reference samples: ANG (Anorthosite rock), GIT-IWG, BEN (Basalt rock), BHVO1 (Basalt rock), BIR-1 (Basalt rock), from USGS, Reston, USA, JR-1 (Rhyolite), JR-2 (Rhyolite), from GSJ, Japan, MAG-1 (Marine mud), USGS, NIM-L (Lujavrite), MINTEK, RGM-1 (Rhyolite), USGS, (Calcareous loam soil), STM-1 (Syenite), USGS, SY-2 (Syenite), CCRMP, Canada. For each sample, the average of three results and the respective standard deviation are listed on the first line; the second line represents the certified values of the reference material. The uncertainty in the results refers to the precision since only one pellet was prepared for each reference material. The accuracy of the results was evaluated by comparing the certified values of the analyzed reference materials. When the certified values are known, the results should ideally be within the confidence interval: $\mathrm{CV} \pm \mathrm{Cl}$.

The fitness for purpose of the results was also evaluated using the quality test proposed by the International Global Geochemical Mapping Program (IGCP) (12), and as performed by Krishna et al. (6) and Enzweiler et al. (13). The differences between the obtained and recommended values are compared by using the expression of $\log$ Cc - $\log$ Cf $£ \pm 0.05-0.3$, where $\mathrm{Cc}$ and $\mathrm{Cf}$ are the certified and found concentrations, respectively. The values of the interval that should be satisfied depend both on analyte concentration and on sample. The sample can be either first or second grade, corresponding to international and in-house reference samples, respectively. Figure 4 shows the plot obtained by applying the IGCP test to the results of $\mathrm{Cl}, \mathrm{F}$, and $\mathrm{Br}$ from Table V. According to IGCP criteria, the reference samples analyzed in this work would be considered firstgrade standards. The test applied in this work for halogens was as follows: the external lines in the plot (for which $\log \mathrm{Cc}-\log \mathrm{Cf} £ \pm 0.15$ was used) were for first grade standards, while the internal lines represent limits for second grade standards $(\log \mathrm{Cc}-\log \mathrm{Cf} £ \pm 0.1)$. From Figure 4 it can be deduced that the method is adequate for geochemical mapping applications.

\section{Precision}

Precision of triplicate analysis is expressed as the relative standard deviation (\%RSD). Although the RSD varies from sample to sample and for each element, the range of RSD based on the highest and lowest concentrations gives a good indication of the precision at high concentration levels. Figure 5 shows the relative standard deviation (\%RSD) of the elemental concentrations measured for the halogens $(\mathrm{Cl}, \mathrm{F}$, and $\mathrm{Br})$. The larger relative standard deviations between our results and the published values may be attributed to either the heterogeneous distribution of the halogens in the rock samples or to contamination of the rock samples during preparation. However, the first observation is that the variations in data would not depend on the absolute concentrations of the halogens, but mainly on the nature of the geological material, since they are systematically higher in rhyolites (JR-1, JR-2, RGM-1), syenites (STM-1, SY2 ), than in basalts (BEN, BHVO-1, BIR-1) (Figure 5). This is likely related to the incompatible behavior of halogens in magmas, leading to their concentration in residual 


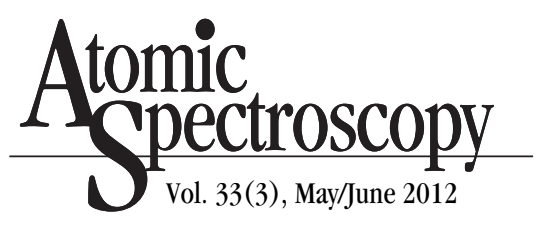

melts or in some halogen-rich accessory minerals, which could be heterogeneously dispersed in differentiated magmas, particularly in granites and rhyolites. On the other hand, although halogen concentrations are lower in basalts, they are much more homogeneous and more suitable as RMs for halogens.

In general, the wavelength dispersive spectrometer (WDS) results have the smallest RSDs, which is consistent with all standards and the sequential measurement of the elements. The WDS, however, has good precision and sensitivity and is less prone to inter-element interferences than other X-ray analytical techniques. Although matrix correction procedures are relatively well understood in X-ray analysis, some of the correction models produce more accurate results than others $(14,15)$. Our results compared with literature data indicate that the use of geological reference materials for characterizing the analytical performance of volatile elements in pressed pellet form is a good medium rather than using the solution form. Moreover, when volatiles like $\mathrm{Cl}, \mathrm{F}$, and $\mathrm{Br}$ are measured on bulk rock samples, especially in magmatic rocks, the larger heterogeneities of these elements are in fact the main source of analytical bias.

\section{CONCLUSION}

Halogen ( $\mathrm{Cl}, \mathrm{F}$, and $\mathrm{Br}$ ) concentrations were determined in a powdered non-destructive sample in the form of a pressed pellet using X-ray fluorescence (XRF) spectrometry. This method allowed the determination of halogen concentrations in reference materials with good analytical precision and detection limits. The concentrations ranged from 26 to $1200 \mathrm{mg} / \mathrm{kg}$ for $\mathrm{Cl} ; 44$ to 6960 $\mathrm{mg} / \mathrm{kg}$ for $\mathrm{F}$, and 0.71 to $252 \mathrm{mg} / \mathrm{kg}$ for $\mathrm{Br}$. These results indicate that in basaltic samples, the Br concentrations are low and homogeneous, while the $\mathrm{Cl}$ and $\mathrm{F}$ concentrations
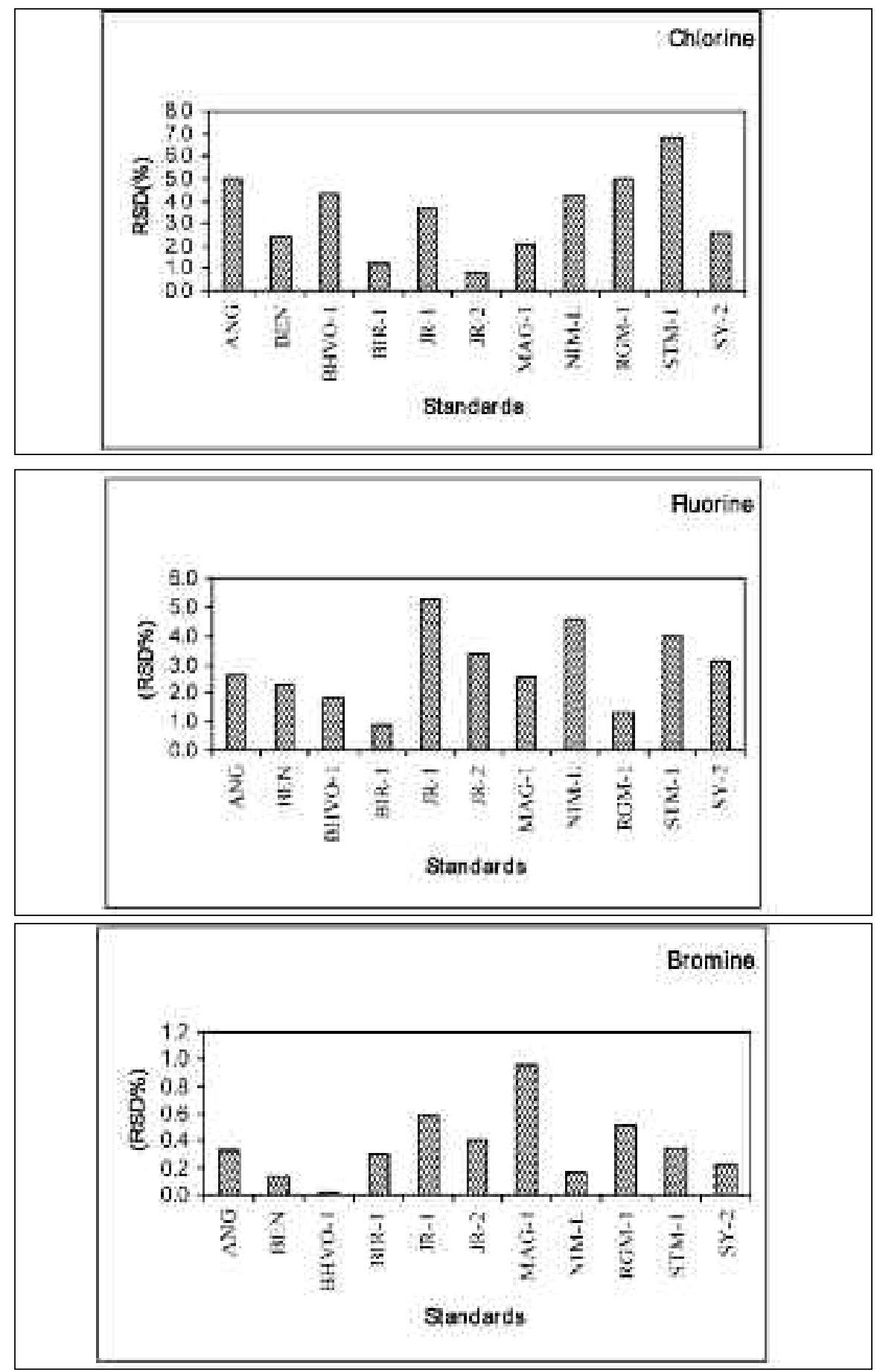

Fig. 5. Relative standard deviation (\%RSD) on y-axis for halogen concentration, and standards are indicated on $x$-axis. 
are highly variable. This may be attributed to the interactions with organic matter or sedimentary material during petrogenetic processes.

The analytical results obtained for halogens showed mean RSD values for $\mathrm{Cl}$ ranging from $0.78 \%$ to $6.7 \%$, for $\mathrm{F}$ from $0.86 \%$ to $5.23 \%$ and for $\mathrm{Br}$ from $0.01 \%$ to $0.59 \%$. The order of suitability of reference materials for halogen determination in this study was Basaltic rocks (BEN, BHVO-1, BIR-1) > Syenites (STM-1, SY-2) > Rhyolites (JR-1, JR2, RGM-1) which can be attributed to the homogeneous analytical results. Further, the relative standard deviation (\%RSD) values can be considered being on the higher side for $\mathrm{F}$ and $\mathrm{Cl}$ than for the $\mathrm{Br}$ values. Nevertheless, the XRF technique used was in good agreement for $\mathrm{Br}$, though it was found in lower abundances in rocks, because the detection limits are much lower than the measured concentrations. However, it is difficult to identify exactly the source of error (sample heterogeneity) in some cases, especially for high $\mathrm{F}$ and $\mathrm{Cl}$ concentrations. Consequently, the XRF spectrometer employed is a promising tool for quick screening analysis of environmental and geological samples involving minimum sample preparation.

\section{ACKNOWLEDGMENT}

The authors are thankful to Dr. Mrinal K. Sen, Director, National Geophysical Research Institute, Hyderabad, India, for his support and permission to publish this paper. Thanks are also due to Dr. V. Balaram for his valuable suggestions.

Received February 17, 2012.

\section{REFERENCES}

1. M. Carroll and J.R. Holloway, (Eds.), Reviews of Mineralogy, pg. 30 (1994).

2. Ronald Fuge, Environmental Geochemistry and Health 10(2), 51 (1988).

3. A. Aiuppa, D.R. Baker, and J.D. Webster, Chem. Geol. 263, 1 (2009).

4. A. Michel and B. Villemant, Geostd. Newsl., The J. of Geostd. and Geoanal. 27, 163 (2003).

5. Helene Balcone-Boissard, Agnes Michel, and Villemant Benoit, Geostd. and Geoanal. Res. 33, 4, 477 (2009).

6. A.K. Krishna, N.N. Murthy, and P.K. Govil, At. Spectrosc. 28(6), 202 (2007).

7. N.V. Alov, R.V. Bulgachev, and K.V. Oskolok, J. Soils \& Sediments 1, 164 (2001).

8. G.R. Lachance and F. Claisse, Quantitative X-Ray Fluorescence. Analysis, Theory and Application, John Wiley \& Sons Ltd., London, U.K. (1995).

9. Xie Xuejing. Analyst 120, 1497 (1995).

10. K. Govindaraju, Geostd. Newsl. 18. (Special Issue), 158 pp (1994).

11. R. Jenkins and J.V. Gilfrich,. X-Ray Spectrom. 21, 263 (1992).

12. A.G. Darnley,A. Bjorklund,B. Bolviken,N. Gustarsson, P.V. Koval, J.V. Plant, A. Streenjelt, M. Tauchid, and M. Xuijing, Final Report of IGCP Project 259, Paris, France: United Nations Educational, Science and Cultural Organization (UNESCO), $122 \mathrm{pp}$ (1995).

13. Jacinta Enzweiler and Maria Aparecida, Geostand. Newsl. 28(1), 103 (2004).

14. R. Simon, G. Simon, and M. Buth Hagelstein, Nucl. Instr. and Meth. B 199, 554 (2003).

15. R. Van Grieken, A. Markowicz, and P. Very, X-ray Spectrom. 20, 271 (1991). 